\title{
Elevation of Phosphorus Levels in Serum and Decreased Brain Content of Gangliosides in Rats Following Neonatal Asphyxia
}

\author{
R.N.RASTOGI ${ }^{[32]}$, J.S. Prichard and J.A. LowDEN ${ }^{[33]}$ \\ Department of Paediatrics, University of Toronto, and the Biochemistry Division of the Research Institute, \\ The Hospital for Sick Children, Toronto, Canada
}

\begin{abstract}
Extract
Permanent brain damage commonly follows asphyxia in the newborn period. A clinical survey of 287 newborn infants with seizures indicated that an elevation of levels of phosphorus in serum was not uncommonly associated with the subsequent demonstration of cerebral damage. Experiments were undertaken to examine the possible relations between these variables.

Newborn rats were placed for 20 minutes in a chamber, which was continuously flushed with nitrogen and contained less than $0.1 \%$ oxygen (micro Scholander and gas-liquid chromatography). During this period they became cyanotic and made gasping respiratory movements. Serial measurements of levels of calcium, phosphorus and urea nitrogen in serum were made after the rats were removed from the chamber. In comparison with the litter-mate controls, animals subjected to the insult had a significant transient elevation in phosphorus levels 24 hours after the insult (table I). Calcium and urea nitrogen levels were unchanged. There was no histological evidence of renal damage. Subsequently, the experimental rats grew more slowly than their litter mates (table III) and demonstrated more apprehensive behavior. The survivors were killed at 10 weeks of age and the glycolipid $\mathrm{N}$-acetylneuraminic acid (NANA) levels were determined in extracts of cerebral hemispheres. In the experimental animals, the glycolipid NANA content of brain was reduced to $1.90 \pm 0.10 \mu \mathrm{moles} / \mathrm{g}$ wet weight (normal $2.13 \pm 0.09$ ), although the total weight and cholesterol content of cerebral hemispheres did not differ between the two groups.
\end{abstract}

\section{Speculation}

The low level of glycolipid NANA extracted from brains of animals subjected to hypoxia during the neonatal period suggests a decrease in the quantity of dendritic membrane in these animals at ten weeks of age. Neonatal asphyxia may have caused some damage to the neuronal membrane or inhibited its normal development. During the period immediately following the insult, intracellular phosphate was lost through the damaged membrane. Subsequently, and as a consequence, the affected neurones failed to develop normally. The rise in levels of phosphorus in serum 24 hours following hypoxic insult may reflect a widespread effect on membranes of cells throughout the body. 


\section{Introduction}

Asphyxia in the perinatal period is one of the most common causes of permanent brain damage in the young child $[5,27]$.

Clinically, it is difficult to demonstrate neuronal damage in newborn infants since their activity is not dependent upon their cerebral hemispheres [4, 23]. Electroencephalography has been of little help [22]. An observation made on 287 newborns with seizures at The Hospital for Sick Children suggested another approach. Some of these infants had significant elevations in levels of phosphorus in serum. It seemed possible that neonatal asphyxia and seizures might be causally or temporally related to this finding.

To test this hypothesis, newborn rats were subjected to asphyxia and serial measurements of calcium and phosphorus levels in serum were made. Twenty-four hours following insult, those placed in the chamber had levels of phosphorus in the serum significantly higher than those of the litter-mate controls.

Biochemical estimation of glycolipid N-acetylneuraminic acid (NANA) in lipid extracts of brain indicated that these animals had smaller amounts of cerebral gangliosides than litter-mate controls. This finding suggests that the asphyxiated animals had suffered measurable neuronal loss or damage.

\section{Materials and Methods}

Newborn rats, less than one hour of age, were placed in a chamber consisting of a dessicator jar of 10-liter capacity closed at the top by a rubber stopper with three holes (fig. 1). A cylinder of nitrogen was attached to one hole, while a second hole was used as the gas outlet. An air-tight plastic cage with a capacity of 150 $\mathrm{ml}$ was placed in the jar. To the floor of the cage was attached a lever which, when pressed, would allow the contents of the cage to fall to the bottom of the jar. The lever projected through the third hole in the rubber stopper. A thermometer was placed in the dessicator.

There were ten separate experiments involving 184 newborn rats from twenty litters. In each, two litters of rats were used. Half of each litter was asphyxiated and the remaining animals were kept as controls.

The rats to be asphyxiated were placed in the plastic chamber in the jar, and the jar was sealed with the rubber stopper.

A steady flow of nitrogen, at two liters per minute, was passed through the chamber for a period of five minutes. At the end of this time, a sample of the exhaust gas was analysed for oxygen content by the micro Scholander method [24] and by gas-liquid chromato-

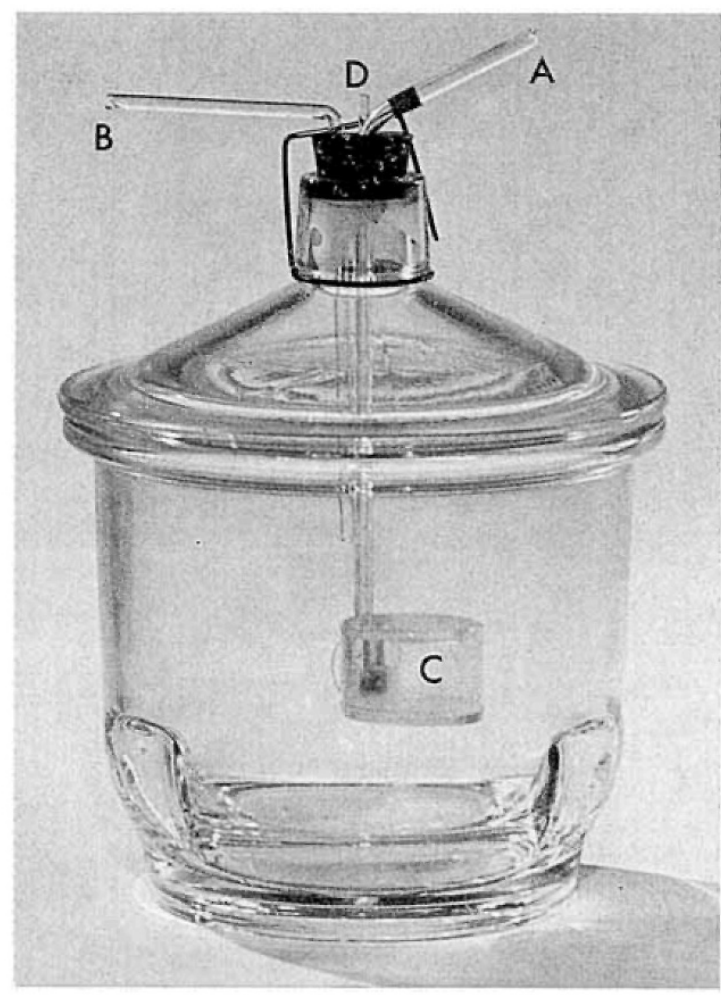

Fig.1. Dessicator jar for asphyxia of newborn rats. A. Port for inflow of nitrogen. B. Port for outflow. C. Airtight plastic cage to contain rats. D. Lever to open cage bottom and dump rats into atmosphere of low oxygen $(<0.1 \%)$.

graphy. The oxygen content was less than $0.1 \%$. Repeated analyses throughout the course of the experiment gave identical results.

The cage-opening lever was then pressed, and the rats were allowed to fall to the bottom of the jar. Nitrogen flow through the jar was continued at the same rate for a further period of twenty minutes. During this time the rats made only gasping respiratory movements and rapidly became cyanosed. They were then removed from the jar and returned to the mother. The experiment was conducted at a room temperature of $21 \pm 1^{\circ}$. In a pilot study, it was found that twenty minutes was the longest time that newborn rats could be kept in the nitrogen atmosphere of the jar without the majority dying. The litter-mate controls remained with the mother and were not placed in the jar. To obtain blood samples, the rats were decapitated with sharp scissors and lightly held upside down over a tube. From each rat, two or three drops of blood could be collected without squeezing. Sets of two or three rats 
were bled at each interval, 3 hours, 24 hours, 3 days and 6 days following insult, and the blood from each set was pooled to provide sufficient volume for chemical analysis. Serum was separated and calcium was estimated by microtitration using EDTA [20]. Inorganic phosphorus was estimated using the method of Frske and SubBarow [7], and blood urea nitrogen was measured by an automated procedure [19]. Kidneys were removed from the infant animals, fixed, sectioned and stained for light microscopy.

Twenty-five rats, 15 asphyxiated in the newborn period and 10 controls, were kept to an age of 10 weeks. They were weighed at regular intervals and their behavior observed. At this time the animals were decapitated and bled, and the cerebral hemispheres were rapidly removed. When using a brain from such small animals as rats, it is often difficult to obtain exactly comparable samples. Great care was taken in this study, therefore, to remove only cerebral hemispheres. To demonstrate that samples were chemically similar, all brains were assayed for cholesterol content and dry weight. White matter normally contains more cholesterol and less water than gray. Significant variations would thus result if the tissue samples contained different amounts of white matter. The figures in table II indicate that the sampling procedure was reproducible.

The hemispheres from each rat were then weighed and homogenized separately in 20 volumes chloroform: methanol $(2: 1 \mathrm{v} / \mathrm{v})$. The extract was filtered and partitioned into aqueous and chloroform layers according to Folch et al. [8]. Following dialysis of the upper phase, the glycolipid NANA content of the brain was assayed, using Bial's orcinol reaction [10]. The lower phase lipids from the Folch extraction were made to a volume of $25 \mathrm{ml}$ with methanol, and aliquots $(0.5 \mathrm{ml})$ of this phase were assayed for cholesterol by gas-liquid chromatography [13] using cholestane as an internal standard.

\section{Results}

In the asphyxiated rats, there was a rise in the level of phosphorus in serum which reached a maximum at twenty-four hours and returned to normal by the third day (table I). The level of calcium in serum rose gradually in both groups but these were not significantly different. There was no significant change in levels of phosphorus in the serum in the control group. Blood urea nitrogen was unchanged throughout the study in both groups (table I). By light microscopy, there was no significant difference in the kidneys of either group at any of the four intervals in which the young rats were killed.

The cholesterol and glycolipid NANA contents of experimental and control rat brains are listed in table II. Although there is no significant difference in the wet weight or cholesterol content between the two groups, the decrease in glycolipid NANA is significant. Aliquots of the dialysed upper phase were freeze-dried and the dry material chromatographed on thin-layer silica gel plates in propanol: water $(7: 3 \mathrm{v} / \mathrm{v})$. The spots were detected with resorcinol spray. There was no significant difference between the two groups in the relative amounts of the major ganglioside species.

The asphyxiated rats which survived ten weeks showed significant differences in weight gain and behavior when compared to the control group of the same age (table III). The experimental rats weighed

Table I. Effect of asphyxia on levels of phosphorus, calcium and urea nitrogen in serum of newborn rats ${ }^{1}$

\begin{tabular}{|c|c|c|c|c|c|c|}
\hline \multirow{3}{*}{$\begin{array}{l}\text { Time after } \\
\text { asphyxia }\end{array}$} & \multicolumn{2}{|c|}{ Phosphorus } & \multicolumn{2}{|c|}{ Galcium } & \multicolumn{2}{|c|}{ Urea nitrogen } \\
\hline & Control & Experimental & Control & Experir & Control & Experimental \\
\hline & \multicolumn{2}{|c|}{$\mathrm{mg} / 100 \mathrm{ml}$} & \multicolumn{2}{|c|}{$\mathrm{mg} / 100 \mathrm{ml}$} & \multicolumn{2}{|c|}{$\mathrm{mg} / 100 \mathrm{ml}$} \\
\hline 3 hours & $\begin{array}{l}5.20 \pm 0.44 \\
(30)\end{array}$ & $\begin{array}{l}5.97 \pm 0.43 \\
(30)\end{array}$ & $\begin{array}{l}8.09 \pm 0.13 \\
(30)\end{array}$ & $\begin{array}{l}8.03 \pm 0.16 \\
(30)\end{array}$ & $\begin{array}{l}32.8 \pm 2.9 \\
(4)\end{array}$ & $\begin{array}{l}33.5 \pm 2.5 \\
(4)\end{array}$ \\
\hline 24 hours & $\begin{array}{l}5.42 \pm 0.44^{2} \\
(30)\end{array}$ & $\begin{array}{l}7.91 \pm 0.36^{2} \\
(30)\end{array}$ & $\begin{array}{l}7.95 \pm 0.14 \\
(30)\end{array}$ & $\begin{array}{l}7.91 \pm 0.17 \\
(30)\end{array}$ & $\begin{array}{l}32.6 \pm 9.3 \\
(4)\end{array}$ & $\begin{array}{l}31.5 \pm 5.8 \\
(4)\end{array}$ \\
\hline 3 days & $\begin{array}{l}5.08 \pm 0.43 \\
(20)\end{array}$ & $\begin{array}{l}5.75 \pm 0.62 \\
(20)\end{array}$ & $\begin{array}{l}8.53 \pm 0.15 \\
(20)\end{array}$ & $\begin{array}{l}8.63 \pm 0.19 \\
(20)\end{array}$ & $\begin{array}{l}31.0 \pm 2.7 \\
(4)\end{array}$ & $\begin{array}{l}31.0 \pm 0.8 \\
(4)\end{array}$ \\
\hline 6 days & $\begin{array}{l}5.74 \pm 0.58 \\
(12)\end{array}$ & $\begin{array}{l}5.88 \pm 0.94 \\
(12)\end{array}$ & $\begin{array}{l}9.28 \pm 0.15 \\
(12)\end{array}$ & $\begin{array}{l}9.52 \pm 0.25 \\
(12)\end{array}$ & $\begin{array}{l}35.2 \pm 4.7 \\
(4)\end{array}$ & $\begin{array}{l}31.5 \pm 5.0 \\
(4)\end{array}$ \\
\hline
\end{tabular}

1 Values represent mean $\pm \mathrm{SE}$ with number of animals in parentheses.

2 These values significantly different $(\mathrm{p}<0.001)$. 
Table II. Effect of asphyxia in the newborn period on rat brain lipids at ten weeks of age

\begin{tabular}{lcc}
\hline Lipid & $\begin{array}{c}\text { Content: } \mu \text { mole/g wetweight } \\
\text { of brain }\end{array}$ \\
\cline { 2 - 3 } & Experimental & Control \\
\hline Glycolipid NANA & $1.90 \pm 0.10$ & $2.13 \pm 0.09$ \\
$\begin{array}{l}\text { Cholesterol } \\
\text { Wet weight (g) of } \\
\quad \text { cerebral hemispheres }\end{array}$ & $1.34 \pm 0.2 \pm 6.7$ & $34.2 \pm 5.2$ \\
No. of animals & 15 & $1.33 \pm 0.09$ \\
\hline
\end{tabular}

1 The values listed are mean values \pm SD.

Duplicate determinations were done on lipid extracts from each animal.

Table III. Effect on weight gain of asphyxia in the neonatal period

\begin{tabular}{|c|c|c|c|c|}
\hline \multirow{2}{*}{$\begin{array}{l}\text { Age in } \\
\text { weeks }\end{array}$} & \multicolumn{2}{|c|}{ Normal rats } & \multicolumn{2}{|c|}{ Asphyxiated rats } \\
\hline & Male & Female & Male & Female \\
\hline \multirow[t]{4}{*}{7} & 244 & 160 & 218 & 141 \\
\hline & 230 & 165 & 217 & 149 \\
\hline & 235 & 162 & & 153 \\
\hline & 225 & & & 147 \\
\hline Mean & 233 & 162 & 217 & 147 \\
\hline \multirow[t]{2}{*}{10} & 373 & 185 & 328 & 153 \\
\hline & 368 & 179 & 332 & 162 \\
\hline Mean & 370 & 182 & 330 & 158 \\
\hline
\end{tabular}

All animals were weighed while fasting. Weights in grams.

less and tended to be more shy and apprehensive, hiding in the corner of the cage when approached. The control rats would quickly learn to recognize the person feeding them. Asphyxiated rats did not seem able to learn in the same way as did the controls; their learning capacity is currently being examined by psychological techniques.

\section{Discussion}

In this study, newborn rats were exposed to a standard period of asphyxia. While they all demonstrated hyperventilation initially, when placed in the low oxygen atmosphere, their breathing rapidly became shallow and they developed cyanosis. Effectively, they thus were not only hypoxic, but hypercarbic as well. The experimental model in some ways, therefore, mimics postnatal asphyxia in the human infant.

The results listed in table I show a striking difference in levels of phosphorus in serum between the asphyxiated animals and the controls. The rising phosphorus was not apparent immediately after the asphyxia but developed in the subsequent 24 hours. Three days after birth levels of phosphorus in serum were again within normal limits.

Failure to thrive and apparent behavioral changes are difficult to assess in rats, and a more quantitative assay of brain damage was required. Gangliosides are $\mathrm{N}$-acetylneuraminic acid-containing glycolipids and are located almost exclusively in dendritic membranes of neurones [15, 29]. When the distribution of the major ganglioside species is unchanged, the determination of glycolipid NANA provides a good measurement of the amount of gangliosides in the tissue. In recent years, several different methods of extraction and assay of cerebral gangliosides have been described $[25,26,28]$. In certain cases these methods isolate larger quantities of glycolipid NANA than the method we have used. The extra ganglioside we do not measure may remain in the tissue or in the lower phase during partitioning.

Gatr and Berman [9] have shown that in TaySachs disease, some gangliosides remain in the lower phase of a standard Folch-type [8] extraction. When extracting gangliosides from normal brain, however, they found that no glycolipid NANA remained in the washed lower phase. In our animals, however, the gangliosides had a normal distribution on thin layer chromatography, and random samples of lower phase lipids in both groups were free of NANA.

Although it is possible that we have not extracted all of the ganglioside from the rat cerebral hemispheres, both groups of animals were treated in the same fashion; thus the relative amounts of glycolipid NANA are comparable.

The results indicate an absolute decrease in the amount of all ganglioside species in the experimental animals. Because gangliosides are neuronal membrane lipids which accumulate during the period of dendritic expansion [3,17] and because they are located in nerveending particle fractions [29], it seems reasonable to suggest that the decrease in the total quantity of gangliosides extracted from brain may represent a failure in the normal development of a complete dendritic expansion in the experimental animals.

LOWDEN and Wolfe $[14,16]$ found that gangliosides in brains of adult cats and humans lose $\mathrm{N}$-acetylneuraminic acid during hypercapnia. This finding is probably not related to the changes in the newborn animal.

In the present experiment, the quantity of gangliosides in the brain is decreased, while in the cat studies, the gangliosides contain less NANA than normal. Furthermore, the mechanism of the change in the hypercapneic adults is probably different from the 
apparent inhibition of normal accretion in the rats in this study. BLANKIER and LOWDEN [2] have recently demonstrated that the loss of NANA from gangliosides during hypercapnea is reversible when the animals are adequately ventilated with room air.

There are several possible mechanisms responsible for the increase in the level of phosphorus in serum. For example, it could be the result of increased intake, increased mobilization from bone, abnormal renal excretion, changes in soft-tissue cell membranes with a resultant increase in membrane permeability, or it could be actual cell destruction. The first two possibilities are unlikely for the intake was probably similar in both groups, although the experimental animals actually grew more slowly than the controls. If the rise in the level of phosphorus in serum were due to increased mobilization from bone, one would expect a concomitant change in the level of calcium in serum when in fact there was none.

Renal function, on the other hand, may be depressed by severe hypoxia. There are reports in the literature of proximal tubular damage in newborn human infants with respiratory distress $[11,12]$. Phosphate excretion, however, is affected by changes in glomerular filtration, and elevated phosphorus levels in serum are expected only when there is a profound decrease in the ability of the glomerulus to filter plasma [21]. In newborn rats, glomerular filtration is the major mechanism for handling phosphorus while tubular reabsorption is small. Thus the lesion in the kidney, which is usually produced by hypoxia, is unlikely to significantly affect the level of phosphorus in serum.

The normal values of phosphorus levcls in serum at three hours and at three days after asphyxia, and the normal blood urea nitrogen and histological appearance of the kidney are not consistent with a severe renal lesion. Thus, one must assume that the phosphorus comes from cells which were damaged at least to the extent of losing the normal capacity of living cell membranes to maintain gradients.

The brain of a newborn accounts for between 5 and $10 \%$ of the total wet weight of the animal. Phosphate content of brain is high and the turnover is normally very rapid, but the exchange of labelled phosphate between blood and brain is low [18]. In conditions of asphyxia, the rate of exchange of $\mathrm{P}^{32}$ between plasma and brain is greatly increased, indicating some alteration in the exclusion properties of the so-called 'bloodbrain barrier' $[1,6]$. A similar mechanism could be operating in these rats. Although the rise in levels of phosphorus in the serum may in part reflect the release of phosphorus from neuronal tissue, the change is of such a magnitude as to suggest an effect on cell membrane permeability to phosphorus occurring in most tissues of the body.
Gangliosides are located mainly in neuronal membranes. Studies of lipids in rat brains during development indicate that the major increase in gangliosides occurs prior to myelination [3, 17], probably during the period of dendritic expansion. In this experiment, the brains of adult animals that had been subjected to asphyxia in the newborn period contained less ganglioside than normal brains but were similar in total weight and cholesterol content. Thus, it would appear that asphyxia had damaged the neuronal membrane and prevented normal development, although it has not hindered growth or even myelination in the organ.

\section{References and Notes}

1. Bange, C. and Peres, G.: Regulation of blood phosphorus in the rat. II. Action of hypercapnia alone or associated with hypoxia. Arch. Sci. physiol. 17: 247-253 (1963).

2. Blankier, J. and Lowden, J.A.: The incorporation of $\mathrm{N}$-acetylneuraminic acid into gangliosides following hypercapnia (in preparation).

3. Burton, R. M.: Lipids and lipidoses (ed. SchertLER, G.), p. 123 (Springer, New York 1967).

4. Conel, J.L.: The post-natal development of the human cerebral cortex, vol.6. - Cortex of the twenty-four month infant (Harvard University Press, Cambridge, Mass. 1959).

5. Drage, J.S. and Berendes, H.: Apgar scores and the outcome of the newborn. Pediat. Clin. N. Amer. 13: 637-643 (1966).

6. Ernster, L. and Herlin, L.: The fate of intracisternally injected tracer phosphate in the rabbit, normally and as influenced by sulphydryl reagents. A kinetic approach to the mechanism of the bloodbrain barrier. J. Neurochem. 6: 267-276 (1961).

7. Fiske, C.H. and Subbarow, Y.: The colorimetric determination of phosphorus. J.biol. Chem. 66: 375-400 (1925).

8. Folch, J.; Lees, M. and Sloane-Stanley, G.H.: A simple method for the isolation and purification of total lipids from animal tissues. J.biol. Chem. 226: 497-509 (1957).

9. Gatt, S. and Berman, E.R.: Studies on brain lipids in Tay-Sach's disease. II. Solubility properties of gangliosides. J. Neurochem. 10:65-72 (1963).

10. Gotschalk, A.: The chemistry and biology of the sialic acids and related substances (Cambridge University Press, London 1960).

11. Jonsson, B.: Lower nephron nephrosis in asphyxia neonatorum. Acta paediat. (Uppsala) 40: 401-408 (1951).

12. Kwittken, J. and Reiner, L.: Acute tubular 
nephrosis in the newborn infant, a manifestation of anoxia. Pediatrics 33: 380-387 (1964).

13. LOWDEN, J.A.: The quantitative determination of cholesterol in brain lipid extracts using gas-liquid chromatography. J.Chromatogr. 27: 246-249 (1967).

14. LoWDEN, J.A. and WoLfE, L. S.: Effect of hypoxia on brain gangliosides. Nature, Lond. 197: 771-772 (1963).

15. Lowden, J.A. and Wolfe, L. S.: Evidence for the localization of gangliosides in neurones. Canad.J. Biochem. 42: 1587-1594 (1964).

16. Lowden, J.A. and Wolfe, L. S.: Studies on brain gangliosides. IV. The effect of hypercapnia on gangliosides in vivo. Canad.J. Biochem. 42: 1703-1710 (1964).

17. MAKer, H.S. and Hauser, G.: Incorporation of glucose carbon into gangliosides and cerebrosides by slices of developing rat brain. J. Neurochem. 14: 457-464 (1967).

18. Manina, A.A.: Dynamics of the inclusion and distribution of radioactive phosphorus in tissues of the nervous system of white rats. Dokl. Akad. Nauk SSSR, Otd. Biokh. 126: 867-869 (1959).

19. Marsh, W.H.; Fingerhut, B. and Kirsch, E.: Determination of urea nitrogen with the diacetyl method and an automatic dialyzing apparatus. Amer.J. clin. Path. 28: 681-688 (1957).

20. Mertes, S. and FAulkner, W.R. : Manual of practical micro and general procedures in clinical chemistry, p. 53 (Thomas, Springfield, Ill. 1962).

21. Prts, R.F.: Physiology of the kidney and body fluids (Year Book Medical Publishers, Chicago, Ill. 1963).

22. Prichard, J.S.: The character and significance of epileptic seizures in infancy, in Neurological and electroencephalographic correlative studies in infancy (ed. Kellawan, P. and Petersen, I.) (Grune and Stratton, New York 1964).

23. Robinson, R.J. and Tizard, J.P.M.: The central nervous system in the new-born. Brit.med. Bull. 22: 49-55 (1966).

24. Scholander, P.F.: Analyzer for accurate estimation of respiratory gases in one-half cubic centimeter samples. J. biol. Chem. 167: 235-250 (1947).

25. Spence, M.W. and Wolfe, L.S.: The effect of cations on the extractability of gangliosides from brain. J. Neurochem. 14: 585-590 (1967).

26. Suzuki, K. : The pattern of mammalian brain gangliosides. II. Evaluation of extraction procedures, post mortem changes and the effect of formalin preservation. J. Neurochem. 12: 629-638 (1965).

27. Towell, M.E.: The influence of labor on the fetus and the newborn. Pediat. Clin. N. Amer. 13: 575598 (1966).

28. Trams, E.G. and Lauter, C.J.: On the isolation and characterization of gangliosides. Biochim. biophys. Acta 60: 350-358 (1962).

29. Weigandt, H.: The subcellular localization of gangliosides in brain. J. Neurochem. 14: 671-674 (1967).

30. The authors wish to thank Miss M. Danyluk, Mr. G.WATSON and Mr.W.WrLson for technical assistance.

31. This work was made possible by a grant from the Medical Research Council of Canada (grant MA 1602).

32. Dr. Rasrogr was supported by a grant from Rani Ghar Grotto.

33. Requests for reprints should be addressed to: Dr. J.A. LowDen, The Hospital for Sick Children, 555 University Avenue, Toronto 2, Ontario (Canada). 